\title{
DINAMIKA PEMAHAMAN ULAMA TENTANG HADIS DAJJAL (Dari Interpretasi Tekstual Ke Interpretasi Kontekstual)
}

\author{
Pipin Armita ${ }^{1}$ dan Jani Arni ${ }^{2}$ \\ ${ }^{1}$ Universitas Islam Negeri Sunan Kalijaga Yogyakarta, Indonesia \\ ${ }^{2}$ Universitas Islam Negeri Sultan Syarif Kasim Riau, Indonesia \\ pipinarmita@gmail.com
}

\begin{abstract}
This article intends to describe figure of Dajjal mentioned in various Hadith in polar as-sittah and explain how the textual and contextual interpretation about the futuristic hadith. In varied of hadith, Dajjal is described as the biggest slander Allah created at the end of time, but it is also a sign that the apocalypse is coming. Thus as the people know how to characterize the end times, as well as recognize signs of his arrival is urgent. Base on this article the authors describing and tracking hadiths what speaks specifically about the figure of Dajjal thematicly with descriptive-analytic method; by tracking the traditions concerning, takhrij al-hadits, and also i'tibar as-sanad, sanad analysis, honor analysis, and Sharh hadith textual and contextual as well as an analysis of the object of study authors. Based on the author analysis there is the narratives of Ibn Bukhari, it was found that the Messenger of Allah said Dajjal as a stout man rosy-skinned, curly haired, one eye blind and his eyes were like ripe grapes (no shine). The textual tradition describes the figure of Dajjal essentially as described in the text of the hadith. While contextually, some scholars understand that the characteristics of the one-eyed mentioned in the editorial of these traditions is the symbol/metaphor to describe the state of the day after is controlled by a conspiracy to dominate the world, and is associated with Western civilization and the Jews are full of deceit and misguidance and thinking which tends to the world.
\end{abstract}

Keywords: Dajjal, Hadith, Textual, and Contextual.

\begin{abstract}
Abstrak
Artikel ini bermaksud menggambarkan figur Dajjal yang disebutkan di beberapa hadis dalam kutub al-sittah dan menjelaskan bagaimana interpretasi tekstual dan kontekstual tentang hadis-hadis yang berbicara tentang masa lalu. Dalam beberapa hadis, Dajjal itu digambarkan sebagai fitnah besar yang Allah datang pada akhir masa, tetapi dia juga merupakan simbol dari wahyu yang akan datang. Dengan demikian manusia mengetahui bagaimana ciri-ciri akhir zaman, dan mengetahui tanda-tanda kedatangannya adalah suatu hal yang penting. Pada artikel ini penulis akan menjelaskan dan melakukan pelacakan terhadap hadis yang membahas secara spesifik tentang figur Dajjal secara tematik dengan metode deskriptif-analitis; dengan melakukan pelacakan tentang tradisi, takhrij al-hadis, analisis sanad, analisis muru'ah, syarah hadis secara tekstual dan kontekstual sebagai objek dari analisis yang dilakukan oleh penulis. Berdasarkan analisa penulis ada beberapa periwayat dari jalur Bukhari, terdapat wahyu dari Allah yang mengatakan Dajjal adalah seseorang yang gemuk bertubuh kemerahan, rambut
\end{abstract}


keriting, salah satu matanya buta dan matanya seperti buah anggur yang matang (tidak bercahaya). Pemahaman secara tekstual tentang figur Dajjal itu adalah sesuai dengan apa yang digambarkan oleh hadis. Secara kontekstual, para ulama memahami kharakteristik seperti mata yang disebut dalam hadis merupakan sebuah simbol/metafora untuk menjelaskan kontrol terhadap apa yang terjadi hari ini, dan sebagai sebuah konspirasi untuk menguasai dunia, dan sebagai sebuah yang terkait dengan budaya Barat dan Yahudi yang penuh tipu daya, pemimpin yang salah, dan pemikiran yang cenderung duniawi.

Kata Kunci: Dajjal, Hadis, Tekstual, dan Kontekstual.

\section{Pendahuluan}

Abu Fatiah al-Adnani menjelaskan bahwa tanda-tanda kemunculan sosok Dajjal sebagai fitnah akhir zaman, yakni terjadinya kerusakan bertumpuk-tumpuk, kezaliman bertindih-tindih, kesyirikan merajalela, dan kemungkaran sulit dibendung. Kebenaran sulit dibedakan dari kebatilan, halal dan haram sulit dipisahkan. Hal yang baik bercampur baur dengan hal yang buruk. Pada kebanyakan manusia, hati nurani dan fitrah mereka telah rusak dan terkontaminasi. Akibatnya mereka tertipu, terpedaya oleh arus fitnah yang ada. Pada saat itu manusia mudah tergoncang, bahkan karena beratnya fitnah yang dihadapi manusia, ada di antara mereka yang di waktu pagi beriman namun pada waktu sorenya telah menjadi kufr. ${ }^{1}$

Kedahsyatan fitnah akhir zaman yang dibawa Dajjal ini tentu mengharuskan setiap muslim mengenal ciri dan keberadaannya itu. Sumber informasi yang paling akurat adalah teks-teks hadis yang disampaikan Rasulullah saw. Dalam hadis Nabi dijumpai redaksi yang cukup variatif; ada yang menyebutkan Dajjal cukup detail; mulai dari ciri-ciri, kekuatan, hingga kematiannya. Namun, ada juga yang menggambarkan secara umum saja.

Selain itu, hadis menyoroti bahwa kedatangan Dajjal ini di akhir zaman adalah sebagai huru-hara paling besar di antara kekacauan yang pernah ada semenjak Allah Swt menciptakan Adam hingga

${ }^{1}$ Abu Fatiah al-Adnani, Kita Berada Di Akhir Zaman (Surakarta: Granada Mediatama, 2009), 328-329. datangnya hari kiamat nanti. Kedahsyatan fitnah Dajjal ini dengan kekuatan super powernya benar-benar membuat manusia terpedaya kecuali orang yang benar-benar beriman. Sosoknya digambarkan sebagai sosok yang memiliki 'surga' dan 'neraka". Ia memiliki sungai-sungai dengan air yang jernih dan gunung-gunung roti. Alampun tunduk pada perintahnya, jika ia memerintahkan langit untuk menurunkan hujan, maka turunlah hujan, dan jika ia memerintahkan bumi untuk menumbuhkan tumbuhan, maka bumipun menumbuhkannya. Dajjal dengan kekuatan tersebut juga dapat melintasi bumi dengan kecepatan yang luar biasa, bagaikan hujan yang ditiup angin kencang. ${ }^{2}$

Demikian sosok Dajjal yang diceritakan dalam teks-teks hadis Nabi; mulai dari awal kemunculan, ciri-ciri fisik maupun non-fisik. Informasi-informasi yang terkandung dalam teks hadis tersebut tidak serta merta melahirkan sebuah pemahaman yang seragam di kalangan umat Islam. Hal tersebut tentunya merupakan sebuah kewajaran, mengingat informasi dari Nabi yang bersifat futuristik yang kebenarannya belum terungkap hingga waktu yang telah ditentukan. Perbedaan pendapat yang terjadi di kalangan para ulama tentu menjadi hal yang sangat menarik untuk dikaji, khususnya untuk melihat bagaimana dinamika pemahaman ulama tentang hadis-hadis

${ }^{2}$ Yusuf al-Wabil, Yaumul Qiyamah Tanda-tanda dan Gambaran Hari Kiamat Berdasarkan Sumber-sumber Yang Otentik, Terj. As'ad Yasin dan Zaini Munir Fadholi (Jakarta: Qisthi Press, 2006), 297. 
Dajjal sehingga sebaiknya dikupas secara tekstual maupun kontekstual.

Perbedaan pendapat di kalangan para ulama terletak pada pemaknaan antara tekstual dan kontekstual makna redaksi hadis tersebut. Sebagian meyakini secara tekstual, bahwa sosok Dajjal dapat dilihat secara fisik. Namun, di pihak lain juga ada yang mengkontekstualisasikan pemaknaaan hadis tersebut sebagai simbol keburukan dan angkara murka yang menyebarkan kemudharatan dengan skala kecepatan tinggi. Hal ini juga mengisyaratkan bahwa Dajjalis yang dimaksud adalah kaum Yahudi yang saat ini telah menguasai hampir separuh dunia.

Di antara peneliti mutakhir yang menyinggung masalah Dajjal adalah Dr. Yusuf bin Abdullah bin Yusuf al-Wabil dalam karyanya asyrathu as-sa'ah, dan karya Abdullah bin Sulaiman al-Ghafiliy dengan judul yang sama asy-rathu as-sa'ah. Kedua buku ini menerangkan bahwa salah satu tanda akan terjadinya kiamat adalah kedatangan Dajjal di akhir zaman. Dalam dua karya ini para penulis memfokuskan kajian tentang Dajjal dalam satu bab sebagai salah satu tanda-tanda hari kiamat.

Dari sekian banyak kajian yang telah muncul berkenaan dengan Dajjal, penulis mengkerucutkan pembahasan pada kajian hadis-hadis Dajjal. Kajian ini dilakukan dengan langkah operasional melacak dan memaparkan hadis-hadis nabi yang berbicara secara spesifik mengenai sosok Dajjal, kemudian mentakhrij dan membuat i'tibar assanad, analisa sanad, analisa matan, dan syarah hadis secara tekstual maupun kontekstual serta analisa penulis terhadap objek kajian secara tematik, khususnya dalam kutub as-sittah;(1) Shahih Bukhari dalam kitab al-fitan, bab zikru ad-Dajjal dan bab laa yadkhulu ad-Dajjal alMadinah, (2) Shahih Muslim, dalam kitab al-fitan wa asyrathu as-sa'ah, (3) Sunan Abu Daud, kitab al-Malahim bab Khuruju ad-Dajjal, (4) Sunan at-Tirmidzi dalam kitab al-Fitan, (5) Sunan Ibn Majah dalam kitab al-Fitan, dan (6) Sunan anNasai dalam kitab al-Isti'azah.
Dikarenakan banyaknya hadis tersebut, maka penulis tidak mungkin mencantumkan semuanya, dan agar kajian ini lebih fokus, maka penulis membuat klasifikasi hadis berdasarkan pada ciri fisik, sifat, tempat keluarnya, pengikut dan kekuatan luar biasa yang dimiliki Dajjal, serta doa berlindung dari fitnah Dajjal.

\section{Tinjauan Umum Tentang Dajjal}

Dajjal berasal dari bahasa Arab dajala yang berarti al-kholath (mencampurkan, mengacaukan dan membingungkan). Kata Dajjal diambil dari kalimat 'Dajjala al-ba'iru iza thalaahu bil qathiran wa ghattha bihi' (seseorang itu mendajjal unta bila melumurinya dengan aspal dan menutupinya). ${ }^{3}$ Dan seseorang itu berbuat Dajjal apabila ia menyamarkan dan memanipulasi. Maka ad-Dajjal adalah manipulator atau pembohong yang luar biasa. Lafaz ini merupakan bentuk mubalaghah (menyangatkan/intensitas) mengikuti wazan fa'aala, artinya menelurkan kebohongan dan kepalsuan. ${ }^{4}$

Kata Dajjal merupakan isim 'alam bagi al-Masih sebagai seorang pendusta bermata satu, sehingga kalau disebut Dajjal maka yang segera ditangkap pengertiannya adalah $s i$ pembohong tersebut. sejalan dengan makna etimologinya, Ia dinamakan Dajjal karena menutupi kebenaran dengan kebatilan, atau karena menutupi kekafirannya terhadap orang lain dengan kebohongan, kepalsuan dan penipuan. Tapi ada juga yang menyebutkan karena ia menutupi bumi dengan kelompoknya yang banyak. $^{5}$

Nama populernya adalah al-Masih adDajjal. Lafaz al-Masih mengandung dua makna kontradiktif. Al-Masih dapat berarti ash-shiddiq

\footnotetext{
${ }^{3}$ Muhammad Bin Mukrim Bin Manzur al-Afriqy al-Mishry, Lisaan Al- 'Arab, Juz 2 (Beirut: Daar Shaadir, t.th), 236.

${ }^{4} \mathrm{Abu}$ Sa'adaat al-Mubarak Ibn Muhammad al-Jazary, $A n-$ Nihayah....., Juz 4, hlm. 102.

${ }^{5}$ Muhammad Bin Mukrim Bin Manzur al-Afriqy al-Mishry, 236; At-Thahir Ahmad al-Zawiy, Tartiibu al-Qamus al-Muhit 'Ala Thariqati al-Mishbah al-Munir Wa al-Asasu al-Balaghah (Riyadh: Daar Alam Al-Kutub, 1996), 152.
} 
(yang benar/suka kepada kebenaran) dan $a d h$ dhalil al-kazzab (yang sesat lagi pembohong). Maka Isa al-Masih adalah siddiq, sementara al-Masih ad-Dajjal adalah ad-dhalil al-kazzab. ${ }^{6}$ Dalam kitab nihayah fii ghaaribi al-atsar dijelaskan bahwa, ad-Dajjal disebut dengan nama al-Masih salah satunya adalah disebabkan ia memiliki satu mata yang hilang (mamsuhah). ${ }^{7}$

Abu Abdillah al-Qurtuby menyebutkan ada dua puluh tiga variasi bentuk kata dari lafaz al-Masih. Sedangkan pengarang al-Qamus memecahkannya menjadi lima puluh bentuk kata. Penyusun kamus tersebut mengatakan bahwa ia mengurai variasi bentuk kata ini dalam kitab syarhu masyariqi al-anwar dan lainnya). ${ }^{8}$

Dalam penelusuran penulis, kosa kata Dajjal tidak hanya ditemukan dalam literatur Islam saja. Dalam perbendaharaan umat Kristen, Dajjal (antichrist) juga merupakan sosok yang akan datang di akhir zaman nanti, hal ini disampaikan oleh para penafsir Bibel. Meskipun demikian, para penafsir tersebut juga berbeda pendapat tentang wujud dan sosok seorang Dajjal (antichrist): ${ }^{9}$ (1) Anti kristus adalah sosok orang yang biadab (tidak beradab), (2) Sosok naga yang berapi-api, (3) Makhluk bar-bar yang memiliki sepuluh tanduk, dan (4) Makhluk liar yang memiliki dua tanduk seperti domba, dan mampu berbicara seperti naga atau seperti makhluk liar berwarna merah yang memiliki tujuh kepala dan sepuluh tanduk, atau juga diartikan sebagai setan.

Dari pemaparan di atas, baik dalam literatur Islam maupun Kristen, penamaan al-Masih ad-Dajjal/Antichrist, semuanya menunjukkan keburukan yang dimilikinya, yaitu sebagai almasih yang bermata satu, dan ad-Dajjal yang

${ }^{6}$ Muhammad Bin Mukrim Bin Manzur al-Afriqy al-Mishry, 593. ${ }^{7} \mathrm{Abu}$ Sa'adaat Al-Mubarak Ibn Muhammad al-Jazary, AnNihayatu Fii Ghariib al-Hadits Wa al-Atsar, Juz 4 (Beirut: AlMaktabah Al-Ilmiyah, 1979), 798.

${ }^{8}$ Abdullah bin Sulaiman al-Ghafiliy, Asyrathu as-Sa'ah (Arab Saudi: Wizaratu Asy-Syu-un Al-Islamiyah Wa Al-Auqaaf Wa Da'wah Wa al-Irsyad, 1422 H), 93.

${ }^{9}$ Maryam Bakhtyar, "Adaptation and Comparison of Dajjal (antichrist) in Islam with in Christianity," Journal of Islamic Studies and Culture 2, no. 2 (2014). menutup kebenaran dengan kebatilan dan akan muncul di akhir zaman.

\section{Dajjal dalam Hadis}

\section{Redaksi Hadis tentang Dajjal}

Pada bagian ini penulis mencantumkan satu hadis dari sekian banyak hadis yang menyinggung masalah ciri al-Masih ad-Dajjal dalam riwayat Ibn Hibban dalam musnadnya:

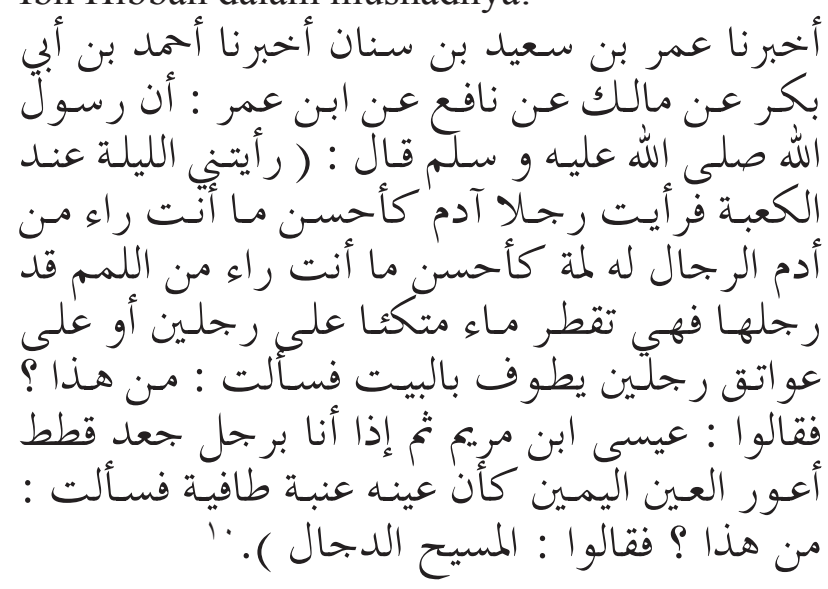

Artinya: Umar bin Sa'id bin Sinan menceritakan kepada kami Ahmad bin Abi Bakar, dari Malik dari Nafi' dari Ibn Umar: Rasulullah Saw bersabda: "ketika saya sedang tidur, saya bermimpi melakukan thawaf di Baitullah, ada seorang lelaki berambut lurus, lalu aku bertanya, siapakah ini? Mereka menjawab Isa bin Maryam. Kemudian aku pergi berkeliling, lalu ada seorang lelaki gemuk berkulit kemerahmerahan, berambut keriting, salah satu matanya buta dan matanya itu seperti anggur yang masak (tidak bersinar). Lalu aku bertanya, siapakah ini?, lalu mereka menjawab: al-Masih ad-Dajjal.

\section{Takhrij Hadis}

Berkenaan dengan hadis pokok yang penulis paparkan di atas, penulis menemukan beberapa riwayat yang memiliki redaksi yang sama atau hampir sama dengan riwayat tersebut. Hadis-

\footnotetext{
${ }^{10}$ Muhamad Bin Hibban Ibn Ahmad Abu Hatim al-Tamimy al-Bisty, Shahih Ibn Hibban Bi Tartibi Ibn Balban, Juz 14 (Beirut: Muasasah Al-Risalah, 1993), 122.
} 
hadis tersebut sebagai berikut:

Shahih Bukhari

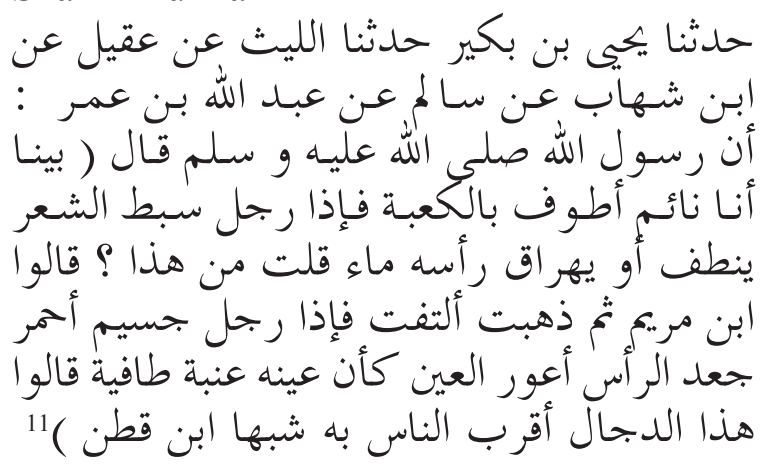

Shahih Muslim

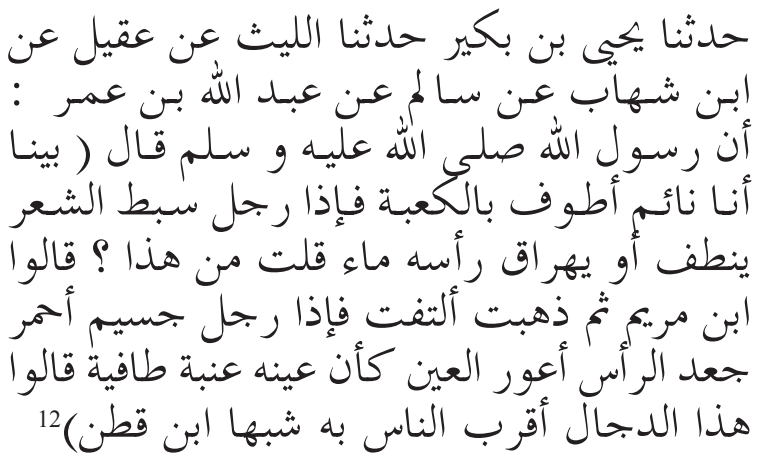

Musnad Ahmad bin Hanbal

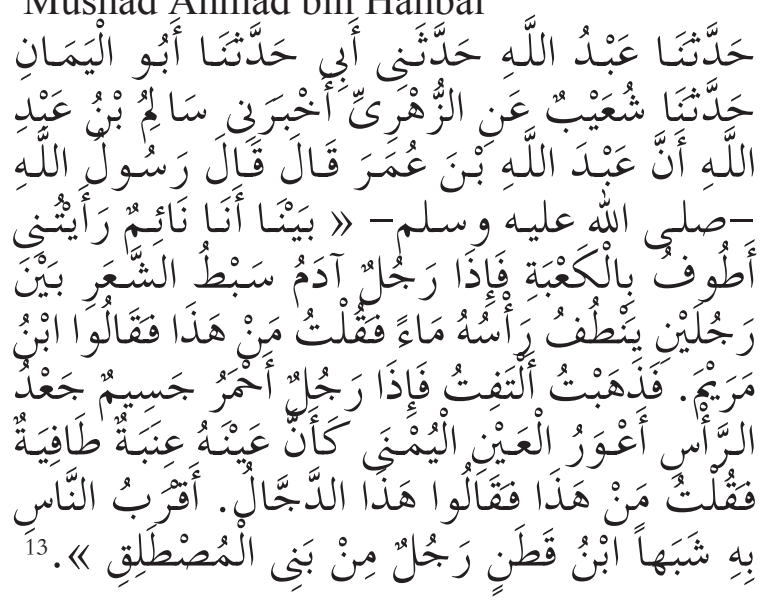

Dengan memperhatikan tiga redaksi hadis di atas, dan membandingkan dengan hadis pokok yang penulis teliti dapat diketahui bahwa semua riwayat tersebut bersumber dari Ibn Umar ra. Namun demikian, letak perbedaan satu sama lain

\footnotetext{
${ }^{11}$ Muhammad Bin Ismail Abu Abdullah al-Bukhari, Al-Jami'u al-Shahih, Bab Zikr Ad-Dajjal, Juz 6 (Beirut: Daar Ibn Katsir, 1987), 2067.

${ }^{12}$ Ibid.

${ }^{13}$ Abu Abdullah Muhammad Bin Hanbal, Musnad Ahmad Bin Hanbal, Juz 1 (Mesir: Mauqi' Wizaratul Auqaf Al-Mishriyah, t.th), 204.
}

adalah pada jalur sanad sesudahnya.

\section{I'tibar al-Sanad}

I'tibar sanad merupakan penyertaan sanadsanad lain untuk suatu hadis tertentu, supaya diketahui apakah ada atau tidak riwayat lain untuk sanad hadis yang diteliti. ${ }^{14}$ Dengan dilakukannya penelitian i'tibar sanad ini, akan diketahui ada tidaknya mutabi' dan syahid dari hadis yang diteliti. Mutabi' adalah periwayat yang berstatus pendukung pada periwayatan yang bukan sahabat, sedangkan syahid adalah periwayat yang berstatus pendukung dari sahabat nabi. ${ }^{15}$

Dalam hadis yang penulis teliti, secara keseluruhan sanad tidak ditemukan adanya syahid. Sebab, seluruh hadis tersebut berasal dari Abdullah bin Umar bin Khattab. Sedang mutabi'nya ada sepuluh orang; Salim, Ibn Syihab, az-Zuhry, alLaits, Syuaib, Uqail, Abu al-Yaman, Yahya bin Bakir, Abdullah, dan ayahnya (lihat lampiran).

\section{Penelusuran Sanad}

Penelusuran sanad merupakan hal yang urgen dalam sebuah penelitian hadis. Ketika sanad sebuah hadis dhaif, maka secara umum penelitian matan tidak diperlukan lagi. Sebaliknya, jika sanad sebuah hadis shahih, maka langkah berikutnya adalah meneliti kredibilitas seluruh jajaran perawi hadis dalam satu jalur sanad hadis yang meliputi aspek ketersambungan (muttasil), kualitas pribadi dan intelektual perawi, serta aspek syadz dan iilat-nya. ${ }^{16}$

\section{a. Umar ibn Sa'id}

Nama lengkapnya adalah umar bin sa'id bin abi husain al-Qurasy an-Nufily al-Makky. Di antara nama guru-gurunya adalah Basyar bin 'Ashim bin Sufyan. Thawus bin Kisan, Abdullah bin Abi Malikah Abdurrahman bin

\footnotetext{
${ }^{14}$ Suryadi dan Muhamad Al-Fatih Suryadilaga, Metodologi Penelitian Hadis (Yogyakarta: Th-Press, 2009), 67.

${ }^{15}$ Umi Sumbulah, Kritik Hadis: Pendekatan Historis Metodologis (Malang: UIN Malang Press, 2008), 31.

${ }^{16}$ Suryadi dan Muhamad Al-Fatih Suryadilaga, 67.
} 
Humaid, Abdurrahman bin Sabith, Ustman bin Abi Sulaiman, Atha' bin Aby Rabah, dan lainlain. Beberapa murid beliau adalah Basyar bin Sary, Hasan Bin Ali bin Ashim, Ruh bin Ubadah, Sa'id bin Salam, Abu Ashim ad-Dahhak Makhlad, Abdullah Ibnu al-Mubarak, Umar bin Tsabit, dan lain-lain.

Mengenai kepribadiannya, Ahmad bin Hanbal mengungkapkan bahwa beliau adalah orang yang tsiqah sama dengan orang-orang yang menulis darinya. Demikian pula menurut Ishaq bin Mansur, Yahya bin Ma'in, an-Nasa-i. Sedangkan Abu Hatim menyebutkan bahwa beliau adalah orang yang shaduq. ${ }^{17}$

\section{b. Ahmad bin Abi Bakr}

Nama lengkapnya adalah al-Qasim bin alHarits bin Zararah bin Mus'ab bin Abdurrahman bin Auf Abu Mus'ab al-Zuhri al-Madiny. Di antara gurunya adalah Imam Malik, Ibnu Abi Hazim, al-Mughirah bin Abdurahman, Muhammad bin Ibrahim bin Dinar, dan lain-lain. Muridmuridnya sangat banyak sekali, di antaranya adalah an-Nasa'i, Abu Ishaq al-Hassyimi, Baqy bin Makhlad, Abu Zur'ah, Abu Hatim, Abdullah bin Ahmad, dan lain-lain.

Zubair bin Bakr menyebutkan bahwa saat beliau wafat beliau merupakan seorang Faqih ahlul Madinah. Siraj menambahkan bahwa beliau meninggal pada bulan Ramadhan $242 \mathrm{H}$ pada usia 92 tahun. ${ }^{18}$

\section{c. Malik}

Nama lengkapnya adalah Malik bin Maghul bin 'Ashim bin 'Uzyah bin Khursyah al-Kufy. Beliau adalah seorang muhaddits yang tsiqah dari Kuffah. Di antara gurunya adalah asy-Syi'by, Abdullah bin Buraidah, Nafi' al-'Umary, Atha' bin Aby Rabah, Talhah bin Musrif, al-Hikam, 'Aun bin Abi Jahifah, Qais bin Muslim, Abdur

${ }^{17}$ Jamaluddin Abi Hujjaj Yusuf al-Mizzi, Tahzibu al-Kamal, Juz 21 (t.tp: Mauqi' Yas'ub, t.th), 364.

${ }^{18} \mathrm{Ibn}$ Hajar al-Astqalany, Tahzibu at-Tahzib, Juz 1 (Mauqi' Yas'ub), 17.
Rahman bin Aswad, Abi Ishaq, dan lain-lain.

Beberapa muridnya adalah Abu Ishaq (juga sebagai gurunya), Syu'bah, ats-Tsaury, Ismail bin Zakariya, Ibnu 'Uyainah, Ibnu al-Mubarak, Syu'aib bin Harab, Ibnu Namir, Waqi', Yahya Bin Sa'id, Abu 'Ali al-Hanafi, dan lain-lain. Ahmad menyebutkan bahwa Malik adalah orang yang tsiqah dalam hadis, demikian pula pendapat Ibn Ma'in dan Abu Hatim serta jama'ah, ia adalah orang yang tsiqah. ${ }^{19}$

\section{d. Nafi'}

Nafi' merupakan imam mufti dan ulama Madinah. Nama lengkapnya adalah Abu Abdullah al-Qurasyi al-'Adwy al-'Umary, budak Ibn Umar ra. Beberapa orang guru beliau, di antaranya adalah Ibn Umar, Aisyah ra, Abu Hurairah, Rafo' bin Khadiij, Abu Sa'id al-Khudry, Ummu Salamah, Abu Lubabah bin Abdul Mundzir, Shafiyah binti Abi 'Ubaid, dan lain-lain. Beberapa muridnya adalah az-Zuhry, Ayyub as-Sijistany, Ubaidillah ibn Umar, saudaranya Abdullah dan Zaid bin Waqid, Humaid ath-Thuwail, ibn Juraij, Malik bin Maghul, dan lain-lain. ${ }^{20}$

Khalaf bin Hisyam al-Bazzar menceritakan pada tahun 226 al-Kattaf bin Khalid al-Makhzumy menyebutkan bahwa Nafi' bertemu dengan ibn Umar di Mekkah. ${ }^{21}$

\section{e. Ibn Umar}

Nama lengkapnya adalah Abdullah bin Umar bin Khattab bin Nafi' bin Abdull Uzzi bin Riyah. Ia lahir sebelum Nabi Muhammad diangkat menjadi Rasul, pada tahun pertama hijriyah. Beliau banyak meriwayatkan hadis Rasulullah Saw, dari ayahnya, Abu Bakar, Utsman, Ali, dan yang lainnya. Di antara muridnya adalah Adam bin Ali, Aslam Maula ayahnya, Ismail bin Abdur Rahman, Umayah bin Abdullah al-Umawi, Salim

\footnotetext{
${ }^{19}$ Muhammad Bin Ahmad Bin Ustman az-Zahaby, Siyaru A'lamu al-Nubala, Juz. 7, 174.

${ }^{20}$ Yusuf Bin Az-Zaky Abdur Rahman Abu al-Hajjaj al-Mizzy, Tahzibu Al-Kamal, Juz. 39 (Beirut: Muassasah ar-Risalah, 1980), 237.

${ }^{21}$ Muhammad Bin Ahmad Bin Ustman az-Zahaby, Juz. 5, 95.
} 
bin Abi al-ja'd, Saad dan lain-lain. ${ }^{22}$

Dari pemaparan di atas jelas bahwa pada riwayat Ibnu Hibban terdapat 5 orang periwayat, yang dimulai dari Ibnu Umar pada tingkatan sahabat, selanjutnya diriwayatkan oleh Nafi', Malik, Ahmad bin Abi Bakar, dan Umar ibn Sa'id. Dari segi kebersambungan sanad, masingmasing periwayat memiliki hubungan guru dan murid, sehingga jalur mereka disebut muttashil/ bersambung. Para Naqid al-hadits juga semuanya menilai mereka periwayat yang tsiqah/ periwayat yang adil dan dhabith. Terpenuhi kebersambungan sanad dan terpenuhi aspek intelektual dan aspek kepribadian para periwayat menjadikan status atau kualitas sanad hadis bernilai shahih.

\section{Penilaian Matan}

Secara metodologis, penelitian matan dapat dilakukan dengan tiga langkah berikut ini: ${ }^{23}$ (a) Meneliti matan dengan melihat kualitas sanadnya, (b) Meneliti susunan lafal matan yang semakna, dan (c) Meneliti kandungan matan.

Pertama, melihat kualitas matan. Melihat matan hadis mengenai Dajjal berdasarkan kualitas sanad, sebagaimana yang telah diungkapkan sebelumnya hadis berstatus shahih. Alasannya seluruh hadis memenuhi kriteria kesahihan hadis, antara lain ketersambungan sanad, dhabith, adil, tidak ada $s a d z$ dan illat. $^{24}$

Kedua, meneliti susunan lafaz. Dari redaksi hadis yang penulis paparkan di atas, baik hadis inti yang berasal yang terdapat dalam Shahih ibn Hibban maupun hadis pendukung yang terdapat dalam Shahih Bukhari, Shahih Muslim, maupun dalam Musnad Ahmad bin Hanbal secara keseluruhan berasal dari riwayat Ibn Umar, dengan redaksi yang hampir sama.

Dari penelitian yang penulis lakukan terhadap hadis utama dan hadis-hadis pendukung dari riwayat lainnya, secara substansial tidak ditemukan

${ }^{22}$ Muhammad Bin Ahmad Bin Ustman az-Zahaby, Juz 3, 204.

${ }^{23}$ M. Syuhudi Ismail, Metodologi Penelitian Hadis Nabi (Jakarta: Bulan Bintang, 1992), 121.

${ }^{24}$ Umi Sumbulah, 31 . perbedaan. Hanya saja, ada penambahan lafaz yang menjelaskan lafaz sebelumnya. Hal ini terdapat dalam riwayat Ahmad bin Hanbal,

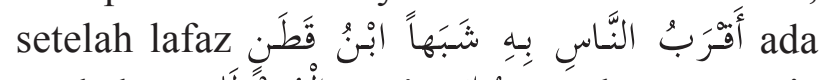

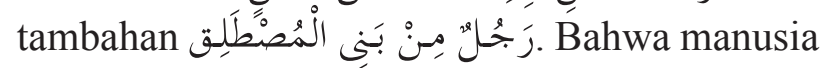
yang paling mirip dengan Dajjal adalah ibn Qatthan, seorang laki-laki dari bani Musthaliq.

Terakhir, hadis Dajjal ditinjau dari kandungannya. Secara eksplisit hadis tersebut tidak bertentangan dengan nilai-nilai al-Qur'an, dan juga hadis shahih lainnya. Setelah meninjau sanad dan matan hadis, penulis menyandingkan maknanya satu dengan yang lainnya. Dalam langkah ini, tidak ditemukan makna-makna kontradiksi yang dapat melemahkan hadis ini. Dengan demikian, dari tiga langkah metodologis di atas dapat disimpulkan bahwa matan hadis ini berstatus maqbul.

\section{Pemahaman Hadis Secara Tekstual dan Kontekstual}

Interpretasi terhadap hadis-hadis Dajjal ini terpecah menjadi dua kelompok, yaitu tekstual dan kontekstual. Yang penulis maksud dengan interpretasi tekstual adalah memahami hadis apa adanya sesuai dengan teks-teks hadis. Sedangkan interpretasi kontekstual adalah memahami hadis yang merujuk pada fakta-fakta yang ada saat ini.

\section{a. Interpretasi Tekstual}

Secara umum, teks hadis yang berbicara tentang Dajjal ini dimaknai secara tekstual; yakni sebagaimana informasi yang terkandung dalam teks. Hal ini bermakna bahwa berita yang disampaikan oleh Rasulullah Saw mengenai hal tersebut adalah sebuah kepastian, yakni Dajjal benar-benar akan datang sesuai dengan fisik yang dijelaskan dalam hadis Rasul tersebut ${ }^{25}$ yaitu; berwujud seorang laki-laki dengan postur tubuh yang gemuk, berkulit merah, rambut keriting, salah satu matanya buta, dan yang satu lagi

\footnotetext{
${ }^{25}$ Zeki Saritoprak, "The Legend of Dajjal (Antichrist); The Personification of Evil In Islamic Tradition," The Muslim World 93 (2003): 291.
} 
seperti warna anggur yang tidak masak serta tidak bersinar. Pendapat ini masih tetap bertahan dan diyakini oleh sebagian kalangan hingga saat ini. Di antara ulama kontemporer yang mewakili pandangan kaum ulama klasik tersebut adalah al-Buthi. ${ }^{26}$

Berdasarkan redaksi-redaksi hadis, Dajjal digambarkan sebagai seorang laki-laki berkulit merah, dengan rambut keriting. Kemudian dalam redaksi hadis lainnya disebutkan bahwa ia juga memiliki dahi lebar, pundaknya bidang, mata yang sebelah kanan buta, sedangkan mata di sebelah kirinya tertutup daging tebal di sudutnya. Di antara kedua mata tersebut terdapat tulisan kafir secara terpisah. Tulisan kafir tersebut adalah tulisan yang hakiki, sesuai dengan lahirnya dan tidak sulit diketahui oleh sebagian orang (kafir), bahkan orang muslim yang buta huruf juga dapat membacanya. ${ }^{27} \mathrm{Hal}$ ini, juga menyimpulkan bahwa Dajjal datang dalam sosok manusia yang hakiki. ${ }^{28}$

Musthofa Abu an-Nasr al-Silbi mengungkapkan, bahwa para peneliti seperti Imam an-Nawawi rahimahullah menyebutkan bahwasanya tulisan tersebut benar-benar ada yang dijadikan Allah sebagai tanda dan bukti kuat yang menunjukkan kekafiran dan kedustaannya. Allah akan menampakkan tulisan tersebut kepada setiap orang Islam, baik yang bisa menulis maupun tidak dan akan menyamarkannya dari setiap orang yang dikehendaki-Nya akan kecelakaan dan terkena

${ }^{26}$ Nama lengkapnya adalah Syaikh Muhammad Sa'id Ramadhan al-Buthi. Beliau merupakan seorang ulama kontemporer yang lahir di Buthan (Turki) pada tahun 1929 M/ 1437 H di tengah keluarga yang religius. Ayahnya adalah syaikh Maula Ramadhan, seorang ulama besar Turki. Setelah peristiwa kudeta Kemal Attaturk, al-Buthi kecil dibawa ikut keluarganya pindah ke Syria. Ia menyelesaikan program doktoralnya pada tahun 1965 di al-Azhar University dengan prediket mumtaz syaf ula. Beliau wafat pada sebuah aksi bom bunuh diri di masjid al-Iman Damaskus Syria pada tanggal 21 maret 2013, dan di makamkan di samping makam Sultan Salahudin al-Ayyubi. Dikutip dari kompasiana.com. Di akses tanggal 15 maret 2016.

${ }^{27}$ Yusuf al-Wabil, 270.

${ }^{28}$ Lihat Abu Abdullah Ahmad Bin Hanbal Bin Hilal Bin Asad al-Syaibani, Musnad Imam Ahmad Bin Hanbal, Bab Anas Bin Malik, Juz. 3 (Mesir: Muassasah Al-Qurthuba, t.th), 207. Rasulullah Saw bersabda:

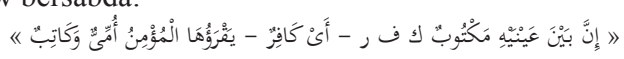

fitnahnya. $^{29}$

Dalam Sunan Abi Daud, disebutkan bahwa Dajjal datang membawa huru-hara dan menyebarkan syubhat di kalangan orang mukmin..$^{30}$ Ia mampu melakukan berbagai kejadian luar biasa dengan izin oleh Allah Swt. Maka pada saat itu ada orang yang mengira bahwa masih ada iman dalam dirinya ketika Dajjal datang justru mengikutinya. ${ }^{31}$ Dengan kemampuannya, seperti sihir, menghidupkan orang mati, dan lain-lain, pengikutnya menjadi kafir sedang mereka tidak menyadarinya. Dengan demikian, pada saat seorang muslim mendengar kedatangannya maka hendaknya ia memohon perlindungan kepada Allah dan menghindar darinya. ${ }^{32}$

Di antara kemampuan-kemampuan Dajjal yang diberikan Allah kepadanya adalah: ${ }^{33}$

a) Menurunkan hujan dan menyuburkan tanah. Tiga tahun menjelang kemunculan Dajjal manusia ditimpa kelaparan hebat, karena Allah memerintahkan bumi agar menahan dan tidak menumbuhkan tanaman. Dalam kondisi demikian, Dajjal muncul dan memerintahkan langit untuk menurunkan hujan dan bumipun menumbuhkan tanaman, lalu Dajjal memerintahkan tempat reruntuhan agar mengeluarkan perbendaharaannya dan semua tunduk kepada perintahnya. ${ }^{34}$

b) Dajjal akan datang membawa Surga dan Neraka yang diikuti dua sungai. ${ }^{35}$

c) Dajjal mampu bergerak dengan cepat di muka

\footnotetext{
${ }^{29}$ Muthofa Abu Nasr as-Silbi, Shahih Tanda-tanda Kiamat dan Kehidupan Sesudahnya, Terj. Ali Murtadho (Jakarta: Pustaka Azzam, 2011), 198.

${ }^{30}$ Lihat Sulaiman Bin al-Asy'ats Abu Daud as-Sijistany al-Azdy, Sunan Abi Daud, Bab Zikru Khuruju Ad-Dajjal, Juz 2 (Mesir: Daar Al-Fikr, t.th), 219.

${ }^{31}$ Yusuf Al-Wabil, 314.

${ }^{32} \mathrm{Abu}$ Thayyib Muhammad Syamsul Haq al-Azhim al-Abadi, Aunul Ma'bud Syarah Sunan Abi Daud, Juz 9, Bab Khuruju AdDajjal, 357.

${ }^{33}$ Muthofa Abu Nasr as-Silbi, 202- 212.

${ }^{34}$ Lihat Hadis Muslim no. 2937, Pembahasan Fitnah-fitnah, Bab Dajjal dan Sifat-sifatnya; Lihat juga Abu Daud no. 4321, Pembahasan Malapetaka, Bab Munculnya Dajjal, dan atTirmidzi no. 2241, Pembahasan Fitnah-fitnah, Bab Dajjal.

${ }^{35} \mathrm{Abu}$ al-Husein Muslim Bin al-Hajjaj Bin Muslim al-Qusyairi al-Naisabury, Al-Jami'u Al-Shahih, Juz 4, Bab Zikr Dajjal Wa Sifatuhu Wa Ma Ma'ahu, 2248.
} 
bumi. Dajjal mampu berpindah dari satu tempat ke tempat yang lain dengan waktu yang sangat singkat untuk menyebarkan kesesatannya, kecuali di Mekkah dan Madinah, secepat hujan yang diterpa angin. ${ }^{36}$

d) Setan-setan menuruti perintahnya dalam mewujudkan misinya. Dalam hadis riwayat Ibn Majah dijelaskan bahwa Dajjal berkata kepada seorang lelaki Badui, "Jika aku dapat membangkitkan kembali ayah dan ibumu apakah kamu akan bersaksi bahwa aku adalah tuhanmu?' lelaki tersebut menjawab 'ya'. Maka dua setan akan menjelma menyerupai ayah dan ibunya, lalu keduanya berkata, "Wahai putraku, ikutilah ia, karena dia adalah tuhanmu." ${ }^{37}$

Namun, kehidupan Al-Masih Dajjal berakhir di tangan Nabi Isa as. Ketika nabi Isa turun Dajjal berada di sekitar Baitul Maqdis dan menghadap ke sana, lalu Isa bertemu dengannya di pintu Lod, ${ }^{38}$ yaitu satu kawasan di Palestina yang berjarak satu farsakh ke Utara Ramalah. ${ }^{39}$

Pada waktu Dajjal melihat Isa, ia pun mencair seperti garam, lalu Isa berkata, "Aku akan memukulmu jika kamu tidak mendapat diriku”. Lalu Isa mengejarnya dan membunuhnya dengan badiknya. Pada waktu itu pengikutnya berantakan lantas dikejar dan dibunuh oleh orang-orang mukmin. Sehingga pohon-pohon dan batu berkata, "Wahai orang muslim, wahai hamba Allah, ini ada orangyahudi di belakangku, kemarilah dan bunuhlah! kecuali pohon ghorqad yang tidak berbuat demikian, karena ia adalah pohon Yahudi". ${ }^{40}$

Dari pemaparan di atas, hadis benar-benar dipahami sebagaimana adanya, bahwa sosok Dajjal akan datang di akhir zaman dengan ciri

\footnotetext{
${ }^{36}$ Lihat Hadis Riwayat Muslim no. 4321, Pembahasan Fitnah Hari Kiamat, Bab Dajjal dan Sifat-sifatnya.

${ }^{37}$ Lihat Hadis Riwayat Ibn Majah no. 4128, Pembahasan Fitnahfitnah, Bab Munculnya Dajjal.

${ }^{38}$ Lihat Muhamad Bin Isa Abu Isa al-Tirmizi al-Sulami, Sunan At-Tirmizi, Bab Qatlu Isa Ibn Maryam Ad-Dajjal, Juz 4 (Beirut: Daar Ihyau Turats Al-Araby, t.th), 515.

${ }^{39}$ Muthofa Abu Nasr as-Silbi, 258.

${ }^{40}$ Yusuf Al-Wabil, 318.
}

fisik dan bentuk yang terdapat dalam redaksi hadis Rasulullah Saw dalam wujud manusia bermata satu.

\section{b. Interpretasi Kontekstual}

Seiring berjalannya waktu, interpretasi tekstual yang disampaikan para ulama klasik mengenai keterangan hadis-hadis Dajjal disebut di atas, perlahan bergeser kepada interpretasi kontekstual yang merujuk pada fakta-fakta yang ada saat ini. Keberadaan Dajjal yang disebutkan dalam hadis tersebut dipahami sebagai sebuah metafora untuk melambangkan/menyimbolkan penipuan dan sifat materialisme. Kelompok ini diwakili oleh Muhammad Abduh dan Rasyid Ridho. Setelah dua kelompok ini, beberapa ulama melangkah lebih jauh lagi dalam memahami teks hadis tersebut dan mengidentifikasi peradaban barat sebagai antikristus/ Dajjal. Di antaranya adalah Muhammad Asad. ${ }^{41}$

Asad mengidentifikasi peradaban Barat sebagai gerakan anti-kristus/Dajjal. Hal ini tergambar dari kehidupan Barat yang tidak memandang nilai-nilai spiritualitas dan hanya memandang pada materi. Dalam pandangan Asad, hal tersebut juga tergambar dari perkembangan teknologi Barat yang jauh melampaui kekuatan manusia dan menciptakan keajaiban. Sehingga jarak jauh dapat diperpendek, adanya sistem irigasi canggih bahkan mampu menstimulasi hujan, dan sistem mesin canggih yang memungkinkan untuk menambang harta karun yang tersembunyi. Bahkan, kecanggihan tersebut seolah mampu menghidupkan orang mati dengan teknologi medis. Hal-hal ajaib seperti ini, mengindikasikan adanya kekuatan super/kekuatan tuhan. Sehingga

\footnotetext{
${ }^{41}$ Nama lengkapnya adalah Mohamad Asad Leopold Weiss. Asad lahir di Livow, Austria pada tahun 1900 M. pada umur 22 tahun ia mengunjungi Timur Tengah dan selanjutnya menjadi wartawan luar negeri di harian "Frankfurter Seitung". Dan setelah masuk Islam ia pergi dan bekerja di seluruh dunia Islam, mulai dari Afrika Utara sampai Afganistan bagian Timur, dan setelah mempelajari Islam beberapa tahun, ia telah menjadi seorang muslim terpelajar dan terkemuka di abad ini. Di kutip dari http://media.isnet.org/ islam/mengapa/asad/html. Diakses tanggal 15 Maret 2016.
} 
Asad menyimpulkan bahwa peradaban barat adalah antikristus/ Dajjal yang dimaksud dalam hadis tersebut. ${ }^{42}$

Beranjak dari pendapat Asad, Rasyid Ridho mencoba memberikan pengertian baru dengan menghubungkan Dajjal dengan orang-orang Yahudi. Hubungan ini direlevansikan dengan tradisi kenabian yang menggambarkan seorang Raja Zionis dan para pengikutnya. Rasyid Ridho juga menjelaskan, bahwa Yahudi mungkin dapat memanfaatkan pengetahuan mereka tentang listrik dan kimia serta eksak lainnya untuk melakukan 'mukjizat' Dajjal. Hal ini tergambar pada momentum konflik antara Arab-Israel ${ }^{43}$ yang juga memperlihatkan kekuatan super yang mereka miliki sebagaimana yang terdapat dalam redaksi hadis Nabi Saw.

Pertama, Dajjal bermata satu. Mata satu pada Dajjal adalah lambang untuk menggambarkan sebuah kekuasaan yang disebut dengan the one eye of Lucifer dari sebuah gerakan. Mata satu tersebut melambangkan sebuah gerakan Dajjal yang bersifat materiliaristik murni dan sangat anti agama. Hal ini juga sesuai dengan cita-cita Adam Weishaupt (Membangun Dunia Baru 'Novus Ordo Scelerum') atas dasar: satu pemerintahan, dan moneter, serta satu kewarganegaraan.

Mereka mengontrol seluruh kehidupan di muka bumi, menghapuskan nasionalisme, patriotisme, dan menghujat eksistensi agama-agama yang ditudingnya sebagai racun dan dogma yang memenjarakan kebebasan berpikir serta menindas nilai kemanusiaan. Karena, menurut Dajjal, selama manusia masih terkotak-kotak dalam agama mereka tidak akan pernah menikmati nilai kemanusiaan yang universal. Dengan demikian Rasulullah Saw. memberikan simbol 'mata sebelah', artinya mereka membutakan diri dari kebenaran Ilahi, menolak Allah dan Rasulnya. ${ }^{44}$

Kedua, Dajjal pendusta dan memfitnah. Hal ini sudah sangat jelas bahwa gerakan konspirasi

${ }^{42}$ Zeki Saritoprak, 291.

${ }^{43}$ Ibid.

${ }^{44}$ Toto Tasmara, Dajjal dan Symbol Setan (Jakarta: Gema Insani, 2001), 120 .
Dajjal telah membuat dongeng-dongeng serta rekayasa yang sangat canggih untuk mendukung dan menyebarkan kebohongan ajarannya. Dengan kecerdasan dan kekuatannya yang sangat besar, mereka mampu menyebarkan berbagai fantasi dan kebohongan yang disebarkan secara simultan di muka bumi melalui kekuasaan video cracy (kekuatan film) yang telah mereka kuasai ${ }^{45}$ ataupun dengan media lainnya.

Ketiga, Dajjal menawarkan surga, padahal neraka dan begitu pula sebaliknya. Dengan kekuatan intelegensinya yang tinggi kaum Dajjal ini menawarkan berbagai kenikmatan surga dunia yang membius. Padahal surga yang ditawarkannya adalah neraka. Dalam redaksi yang lain disebutkan bahwa Dajjal akan membawa api (neraka) padahal air (surga) dan menawarkan air padahal adalah neraka. Sehingga orang yang selamat harus berani menempuh bahaya menantang api, karena api itu adalah surga yang sebenarnya. Tipuan Dajjal itu tidak akan pernah membutakan hati orang beriman karena dalam hatinya ada Allah. ${ }^{46}$

Jika diitelusuri, pergerakan tersebut mirip dengan dunia konspirasi inteligensi. Dalam dunia intelijen, istilah 'konspirasi' berarti sebuah jaringan yang saling mendukung, bergerak secara terselubung atau gerakan bawah tanah (underground). Konspirasi yang berskala internasional seringkali mampu menguasai dan mengarahkan para pemimpin negara tertentu melalui negosiasi, lobi, serta ancaman-ancaman tertentu bahkan pembunuhan sekalipun. Mereka menjadi bayang-bayang dari sebuah kegiatan dan menjadi aktor intelektual dari sebuah peristiwa tanpa dapat diketahui atau diungkapkan secara faktual (dark case). Gerakan konspirasi zionisme ini didukung oleh para profesional yang terseleksi ketat. Mereka mampu membuat berbagai skenario serta taktik yang diolah dan disempurnakan dari waktu ke waktu, sesuai dengan pengalaman mereka. ${ }^{47}$

\footnotetext{
${ }^{45}$ Ibid., 122.

${ }^{46}$ Ibid., 123.

${ }^{47}$ Ibid., 114-119.
} 
Konspirasi ini adalah tipikal manusia yang tidak mengenal belas kasihan. Mereka dapat membunuh dan menyingkirkan lawan-lawannya guna mencapai tujuan. Gerakan konspirasi ini mempunyai jaringan yang sangat besar didukung oleh dana, sumber daya manusia, serta teknologi yang mutakhir. Hal ini digambarkan dengan binatang melata bawah tanah. Dengan konspirasi itu pula pada dasarnya merupakan ideologi pengkafiran yang telah 'berkembangbiak' menyelusup ke seluruh sendi kehidupan manusia akhir zaman. Mereka membantu dan mengembangkan pemerintah yang ditetapkan dari house of temple washington, Pentagon, dan agen-agen mereka. Pembagian tugasnya juga sudah jelas. Di antara para pemikirnya adalah para penyandang anggota senior iluminasi, menyandang tingkat fremason yang rata-rata pada tingkatan ke-33. ${ }^{48}$

Cita-cita untuk membangun menara Babil yang kedua terus berlangsung dan ditetapkannya millenium yang akan datang sebagai awal dari kejayaan kaum Yahudi untuk menguasai dunia yang akan dibawanya kepada satu pemerintahan, satu ekonomi, satu agama, dan satu kewarganegaraan sebagai wujud dari cita-cita Adam Weishaupt, Novus Ordo Sclorum "Membangun Dunia Baru”. ${ }^{49}$ Demikian terstrukturnya konspirasi ini dan penguasaannya terhadap dunia demikian kuat.

Dari beberapa interpretasi pemahaman hadis kontekstual di atas, yang perlu digarisbawahi adalah pemaknaan redaksi hadis Dajjal secara simbolis dan metafora. Dengan demikian, dapat dipahami bahwa Dajjal bukan makhluk yang 'berwujud' dalam satu tubuh sebagaimana dalam interpretasi tekstual, melainkan sebuah konspirasi besar yang menguasai bumi di akhir zaman.

\section{Analisis}

Setelah memperhatikan teks hadis yang berbicara mengenai sosok Dajjal di atas, maka

\section{${ }^{48}$ Ibid.}

${ }^{49}$ Ibid. paling tidak ada dua kelompok interpretasi dalam memahami hadis tersebut; tekstual dan kontekstual. Pemahaman tekstual hadis merupakan pemahaman sebagaimana redaksi hadis tersebut. Dalam konteks ini Dajjal merupakan:

1. Dajjal merupakan sosok seorang manusia yang berjenis kelamin laki-laki, dengan ciri fisik berikut; berkulit merah, rambut keriting, dahinya lebar, pundaknya bidang, mata yang sebelah kanan buta, dan di antara kedua matanya terdapat tulisan kafir secara terpisah.

2. Dajjal merupakan sosok nyata yang hadir di tengah manusia yang membawa kesesatan dari jalan yang benar, seolah surga. Padahal hal tersebut merupakan kesesatan dan kebathilan yang membawa ke neraka.

3. Dajjal akan muncul dari arah Timur, Khurasan.

4. Kehidupan Dajjal akan berlangsung beberapa lama, lalu kemudian ia akan dibunuh oleh Isa ibn Maryam di Baitil Maqdis.

Adapun secara kontekstual, para ulama mutakhir menilai bahwa hadis Dajjal tersebut merupakan hadis simbolis terhadap tipu daya sebuah adikuasa yang penuh dengan tipu daya dan menyesatkan di akhir zaman. Di samping itu, Dajjal juga sebagai simbol kesesatan yang pada sebagian pendapat dikaitkan dengan peradaban Barat dan orang-orang Yahudi yang dalam konteks kekinian memang penuh dengan kemajuan dan lebih menguasai dunia, baik dari sisi keilmuan maupun teknologi. Dengan kemajuan itu pula, mereka dinilai dapat menciptakan keajaibankeajaiban yang luar biasa. Sehingga hal tersebut mengindikasikan bahwa kekuatan itu merupakan bukti bahwa mereka merupakan kaum Dajjalis yang disebutkan secara simbolis dalam redaksi hadis nabi.

Namun demikian, penulis lebih condong pada interpretasi tekstual dan meyakini bahwa sosok Dajjal yang asli akan datang. Karena dalam teks hadis tersebut Rasulullah telah menjelaskan secara detail ciri dan hakikat keberadaan sang al-Masih ad-Dajjal la 'natullah alaih. Rasulullah 
juga telah menjelaskan secara detail bagaimana kedatangan dan akhir dari seorang Dajjal tersebut. Fitnah akan berakhir saat Nabi Isa diturunkan kembali dan membunuhnya di Baitil Maqdis. Hal ini, menurut penulis, jelas-jelas mengindikasikan bahwa Dajjal yang dimaksud bukanlah Dajjal simbolis sebagaimana yang dijelaskan pada interpretasi kontekstual di atas.

Menimbang pada dua corak interpretasi pemahaman terhadap redaksi hadis Dajjal, penulis menilai terlepas dari kecenderungan pada pemahaman tekstual maupun kontekstual terhadap hadis di atas, Rasulullah memerintahkan kaum muslimin agar berlindung kepada Allah dari fitnah al-masih ad-Dajjal ini, sesuai dengan anjuran-anjuran yang telah disampaikan di atas. Baik Dajjal yang 'hakiki' maupun Dajjal simbolis.

\section{Kesimpulan}

Sosok kedatangan Dajjal di akhir zaman juga merupakan salah satu wacana futuristik yang menuai perbedaan pendapat di kalangan para ulama. Di antara mereka ada yang berpendapat dan memahami Dajjal sebagaimana yang tergambar dalam zahir teks hadis tersebut, yaitu digambarkan sebagai sosok anak Adam yang salah satu matanya buta dan di antara matanya tertulis 'kafir'. Bahkan secara lengkap disebutkan memiliki ciri fisik bertubuh gemuk, berambut keriting, dan memiliki yang tidak bersinar.

Selain itu, ada pula yang mengklaim Dajjal dalam makna simbolis dan metafora. Sehingga kehadirannya bukanlah makna zahir sebagaimana diyakini oleh kaum tekstualis, melainkan lambang dari sebuah kekuatan besar yang berkuasa dalam segala bidang, dan menebarkan kesesatan dan kemudharatan di antara manusia. Namun demikian, hakikat keberadaan Dajjal, baik dalam bentuk hakikat maupun metafora, hendaklah kaum muslimin berlindung darinya. Hal ini sebagaimana petunjuk hadis Rasulullah Saw. dalam redaksi lain yang memerintahkan kaum muslimin berlindung dari fitnah Dajjal dengan petunjuk-petunjuk yang ada, misalnya dengan berlindung ke Mekkah dan Madinah, membaca surat al-Kahfi, dan berdoa mohon perlindungan Allah dari fitnah Dajjal.

\section{Daftar Kepustakaan}

al-Abadi, Abu Thayyib Muhammad Syamsul Haq al-Azhim. Aunul Ma'bud Syarah Sunan Abi Daud.

al-Adnani, Abu Fatih. Kita Berada di Akhir Zaman. Surakarta: Granada Mediatama, 2009.

Ahmad, Abu Abdullah Bin Hanbal Bin Hilal Bin Asad al-Syaibani. Musnad Imam Ahmad Bin Hanbal. Mesir: Muassasah Al-Qurthuba, t.th.

al-Asqalany, Ahmad Bin Ali Bin Hajar Abu Fadhl. Tahzibu At-Tahzib. Beirut: Daar Al-Fikr, 1984.

al-Azdy, Sulaiman Bin al-Asy'ats Abu Daud asSijistany. Sunan Abi Daud. Mesir: Daar Al-Fikr, t.th.

Bakhtyar, Maryam. "Adaptation and Comparison of Dajjal (antichrist) in Islam with in Christianity". Journal of Islamic Studies and Culture 2, no. 2 (2014).

al-Bisty, Muhamad Bin Hibban Ibn Ahmad Abu Hatim Al-Tamimy. Shahih Ibn Hibban Bi Tartibi Ibn Balban. Beirut: Muasasah Al-Risalah, 1993.

al-Bukhari, Muhammad Bin Ismail Abu Abdullah. Al-Jami'u Al-Shahih. Beirut: Daar Ibn Katsir, 1987.

Farid, Ahmad. Min A'lam As-Salaf. Terj. Masturi Ilham. 60 Biografi Ulama Salaf. Jakarta: Pustaka Al-Kutsar, 2008.

al-Ghafiliy, Abdullah bin Sulaiman. Asyrathu As$S a$ 'ah. Arab Saudi: Wizaratu Asy-Syuun Al-Islamiyah Wa Al-Auqaaf Wa Da'wah Wa Al-Irsyad, $1422 \mathrm{H}$. 
Hanbal, Abu Abdullah Bin Muhammad. Musnad Ahmad Bin Hanbal. Mesir: Mauqi' Wizaratul Auqaf Al-Mishriyah, t.th.

al-Jazary, Abu Sa'adaat al-Mubarak Ibn Muhammad. An-Nihayatu Fii Ghariib AlHadist Wa al-Atsar. Beirut: Al-Maktabah Al-Ilmiyah, 1979.

Kompasiana.Com. http://media.isnet.org/islam/ mengapa/asad/html. Diakses tanggal 15 Maret 2016.

M. Syuhudi Ismail. Metodologi Penelitian Hadis Nabi. Jakarta: Bulan Bintang, 1992.

al-Mishry, Muhammad Bin Mukrim Bin Manzur al-Afriqy. Lisaan Al-'Arab. Beirut: Daar Shaadir, t.th.

al-Mizzy, Yusuf Bin az-Zaky Abdurrahman Abu al-Hajjaj, Tahzibu al-Kamal. Beirut: Muassasah Ar-Risalah, 1980.

Muslim, Abu Al-Husein Bin al-Hajjaj Bin Muslim al-Qusyairi an-Naisabury. Shahih Muslim. Beirut: Daar Al-Jiil Beirut, t.th.

------. Al-Jami'u Al-Shahih. Beirut: Daar Ihya At-Turats Al-Araby, t.th.

Saritoprak, Zeki. "The Legend of Dajjal (Antichrist); The Personification of Evil In Islamic Tradition". The Muslim World 93 (2003).
as-Silbi, Muthofa Abu Nasr. Shahih Tanda-Tanda Kiamat Dan Kehidupan Sesudahnya. Terj. Ali Murtadho. Jakarta: Pustaka Azzam, 2011. al-Sulami, Muhamad Bin Isa Abu Isa al-Tirmizi. Sunan At-Tirmizi. Beirut: Daar Ihyau Turats Al-Araby, t.th.

Suryadi dan Muhamad Al-Fatih Suryadilaga. Metodologi Penelitian Hadis. Yogyakarta: TH-Press, 2009.

Toto Tasmara. Dajjal dan Symbol Setan. Jakarta: Gema Insani, 2001.

Umi Sumbulah. Kritik Hadis: Pendekatan Historis Metodologis. Malang: Uin Malang Press, 2008.

al-Wabil, Yusuf. Yaumul Qiyamah Tanda-tanda dan Gambaran Hari Kiamat Berdasarkan Sumber-sumber Yang Otentik. Terj. As'ad Yasin dan Zaini Munir Fadholi. Jakarta: Qisthi Press, 2006.

az-Zahaby, Muhammad Bin Ahmad Bin Ustman. Siyaru A'lamu al-Nubala. T.tp: t.p, t.th.

Zainal Abidin Ahmad. Bukhari Pemuncak Ilmu Hadis. Jakarta: Bulan Bintang, 1975.

al-Zawiy, at-Thahir Ahmad. Tartiibu al-Qamus al-Muhit 'Ala Thariqati al-Mishbah alMunir Wa al-Asasu al-Balaghah. Riyadh: Daar Alam Al-Kutub, 1996. 